\title{
An on-line computer-based system for determining social costs and benefits
}

\author{
STEVEN P. SORRELL, PAULETTE M. SELMI, and JAMES H. JOHNSON \\ Illinois Institute of Technology, Chicago, Illinois 60616
}

\begin{abstract}
An on-line computerized program for determining social costs and social benefits for individuals in psychiatric treatment is described. The use of such a program yields a dollar value indicating how much a patient contributes to society. Mental health administrators and program evaluators can therefore be provided with information regarding the economic impact that their mental health programs have upon society. The program displays a series of multiplechoice questions on a CRT which reflect possible costs and benefits. Through the use of branching logic, unnecessary questioning is omitted. Each item is "costed" such that, upon completion of testing, a cost-benefit index is provided.
\end{abstract}

The use of on-line computer technology has become an increasingly important area of psychological research, especially in mental health delivery. Johnson, Giannetti, and Williams (1976) reviewed numerous studies on the applications of on-line systems in mental health and concluded that this technology is useful to mental health professionals. Clinicians have adapted on-line computer technology to administer, score, and analyze numerous psychological tests (Klingler, Miller, Johnson, \& Williams, 1977). Administrators, as demonstrated by Ravenswood Hospital Community Mental Health Center, have implemented information systems that monitor a client's progress through treatment. The systems also maintain data on the cost and outcome of treatment (Sherman, Note 1). On-line computer technology is also applicable to program evaluation. Klingler et al. (1977) used an on-line system to evaluate a psychiatric unit and found that the use of this technology reduced program costs and the time clinicians required for report writing.

Efficient uses of our resources, as described above, are required so that mental health care can be provided to all persons in need (Lanyon, 1971, 1972). The mental health demands of this country can no longer be met by pretechnical approaches to service delivery. Lanyon (1972) and Lyons (1980) proposed the use of innovative technologies to arrive at more efficient decision-making strategies. However, Sutherland (1977) noted that most professionals in social services are trained to treat patients rather than to administer delivery programs effectively.

Because of this situation, there have been numerous proposals to adopt more efficient methodologies to deliver mental health services. Johnson, Williams, Giannetti, Klingler, and Dittmer (1979) made the analogy between the management of mental health

Requests for reprints and program materials should be sent to James H. Johnson, Department of Psychology, Illinois Institute of Technology, Chicago, Illinois 60616. centers and businesses. Feldman (1972) agreed but cautioned that there is some difficulty in transferring knowledge and strategies from business directly to mental health services. Fishman (1980) proposed a computerized cost-effectiveness methodology for community mental health centers.

However, there are some difficulties in assessing what is the proper output unit in mental health evaluation. Halpern and Binner (1972) suggested a method, "output value analysis," to determine the economic value of treatment. The disadvantage of this method is that it requires the estimation of dollar amounts for psychological improvement. Carter and Newman (1976) designed a system of integrating treatment costs and psychological improvement.

The purpose of this paper is to describe an instrument, the Social Cost Benefit Index (SCBI), that measures many of the costs that society incurs and economic benefits it obtains from an individual who is being treated psychiatrically. SCBI produces a final dollar figure to determine if a patient has been an economic asset or liability to society. One assumption of this index is that treatment should attend not only to subjective emotions, such as self-worth, of the patient, but also to the patient's financial value to society. By knowing information generated by SCBI, administrators can better determine whether their treatment program influences these costs and benefits. By use of the methodologies described above and those of SCBI described here, mental health workers should be able to focus on treatment programs that yield optimal gains for individuals and society.

There have been numerous reports of studies demonstrating the comparison of costs to benefits of institutional vs. community based treatments (e.g., Murphy \& Datel, 1976; Sharfstein \& Nafziger, 1976; Sheehan \& Atkinson, 1974; Stein \& Test, 1980; Test \& Stein, 1980; Weisbrod, Test, \& Stein, 1980). Results have generally shown that although community based treatment 
centers may cost slightly more than institutional settings, the benefits generated by these centers, such as earnings, outweigh those of traditional institutional treatments. Ginsberg and Marks (1977) used an internal rate of return to determine that brief behavioral psychotherapy produced economic benefits for neurotic patients. Since these patients were monitored over 3 years and benefits continued during that period, the internal rate of return produced by therapy was worthwhile. Although the difficulties of monitoring only dollar values have been noted (Alexander \& Messal, 1972; Fox \& Kuldau, 1968; Fox \& Rappaport, 1972), it seems desirable to measure the economic costs and contributions of those receiving psychological treatment.

Gunderson and Mosher (1975) estimated that the cost of schizophrenia alone is between $\$ 12$ billion and $\$ 20$ billion annually. Between $26 \%$ and $41 \%$ of these costs are from treatment and assistance given to schizophrenics. The majority of the other estimated costs are due to the loss of productivity of the individuals. Conley, Conwell, and Arrill (1967) estimated that in 1966 the cost of mental illness was approximately $3 \%$ of our gross national product. The development of these global cost estimates suggests that it is reasonable to measure the efficiency of individual treatment in terms of social costs and benefits. Conley et al. (1967) proposed four areas to monitor in order to determine the cost of mental illness: (1) reduction in productive activity, (2) cost of treatment, (3) cost of illegal and other undesirable behaviors, and (4) intangibles. The present SCBI includes measurement in all of these areas.

\section{PROGRAM DESCRIPTION}

The SCBI was developed to estimate the cost or benefits to society associated with mental health treatment. The program designed for this instrument presents items on a CRT and internally calculates the total costs to society. It then subtracts costs from contributions and yields a social-benefit dollar value that is either positive or negative, depending on whether or not that person was more of a cost or a contribution to society for a given period of time.

The SCBI consists of a series of self-report multiplechoice items that reflect possible costs and contributions to society. Each item on the questionnaire was "costed" by referring to city, state, county, and federal budgets." Average cost figures on a "per call" basis were determined for each item. Overhead costs were included in these averages whenever possible.

The questionnaire was designed for persons 18 years of age and older, because there is often a problem with younger persons when contributions to society are figured. Younger persons are not likely to be working and paying regular taxes. For these cases, it is more appropriate to use the family of origin.

The questionnaire has two basic components: one that figures costs and one that figures benefits. The cost portion is limited to city, state, county, and federal monies. Three general areas are included in the cost portion of the questionnaire: legal, social services, and Veterans Administration benefits. Within legal costs are included: police visits, traffic tickets, arrests, court costs, incarceration, probation, parole, and rehabilitation. Social services include a wide range of areas: public health facilities, mental health services, human services, foster care, medicare, medicaid, social security, welfare, subsidized housing, child and family services, and fire department services, to name a few. Veterans Administration benefits include disability compensation, pension benefits, and survivor's compensation.

Benefits are determined after the cost has been calculated. Included in these benefits are the amount paid in local, state, federal, property, and sales taxes for a given year. ${ }^{2}$ These are added to yield one sum.

After completion of the questionnaire, a hard copy is provided. The format of the output separates costs from benefits. Each cost is labeled and printed in the column. The same format is used for contributions, and that sum is printed out in the form of an equation: contributions - costs $=$ social benefit. The appropriate amounts appear below each variable in the equation. Figure 1 displays a sample SCBI, which lists the costs and contributions of a psychiatric patient over a period of 1 year.

\section{PROGRAM OPERATION}

The program is written in BASIC for operation on a PDP-11/03 computer. Upon execution of the run, operating instructions appear on the CRT display. After all instructions are comprehended, the first item appears and the person responds by pressing a proper response key (e.g., A, B, C). The system then determines, via branching logic, the next appropriate question. The maximum number of items is 100 . For example, if the first question is "Have you had any involvement with the police in the past year?" and the subject responds affirmatively, the next question that is asked is more specific regarding the involvement with the police, such as "Have you ever received a speeding ticket in the past year?" If the first question is answered negatively, the program eliminates all specific questions regarding involvement with the police and branches to the first question of the next category, such as "Have you ever received services from a public health facility in the past year?" Upon completion of the run, a hard copy is automatically provided. One file per person (or family) is stored and the information is retrievable at any time, using the proper codes.

\section{PROGRAM APPLICATION}

The SCBI has a wide variety of applications. Not only is it designed for patients receiving psychiatric treatment, but also it could be used for criminal 


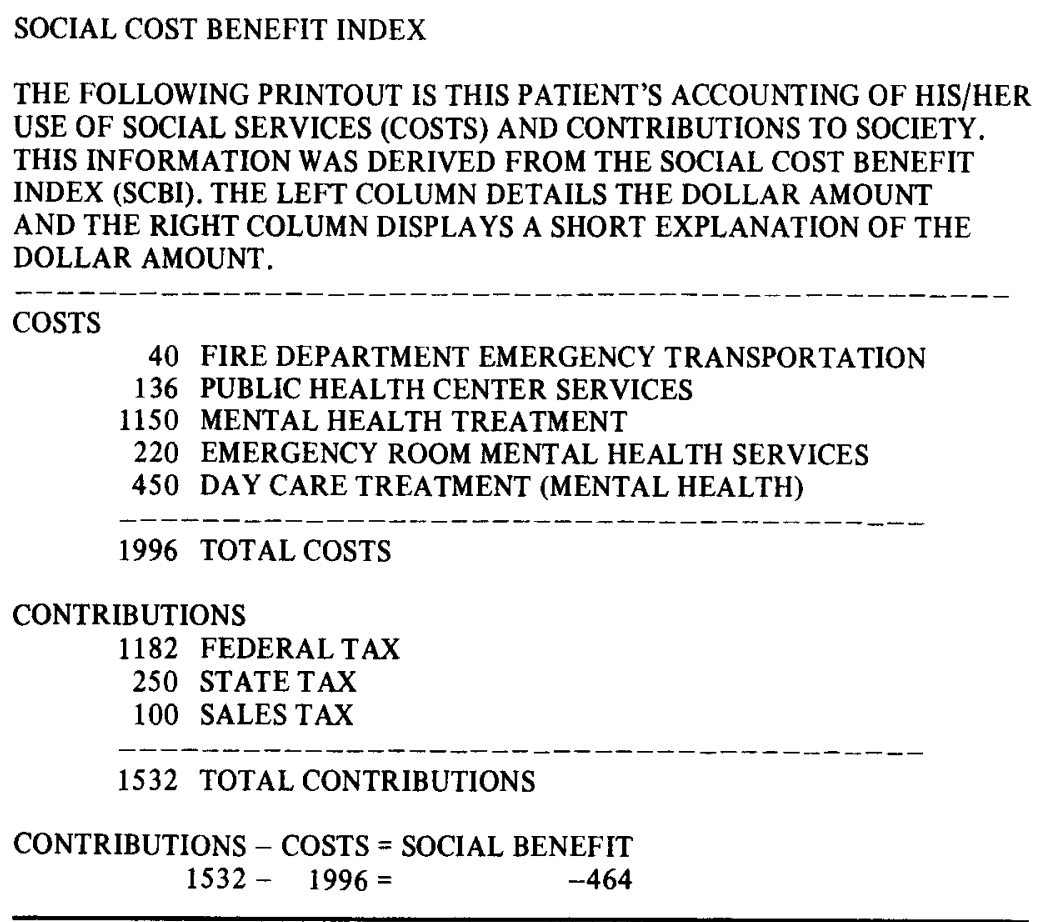

Figure 1. Sample social cost-benefit index.

offenders (such as in probation and parole decisions). This index would provide interesting data on comparisons between different diagnostic groups or psychological treatments. The structure of the program enables mental health administrators to evaluate treatment programs by administering the index of pretreatment and, a year after treatment, to determine whether patients have made a greater economic contribution to society.

\section{SUMMARY}

The SCBI provides program evaluators with an instrument to determine how much, in dollar values, a patient receiving psychiatric treatment contributes to society in the form of taxes and what she/he costs society. Costs are assessed by sampling the frequency with which the patient uses various social services. The importance of determining social cost benefit is based on the rationale that funding agencies require evidence that social service programs are making a contribution to society. The use of this index provides mental health administrators with an assessment of the cost-effectiveness of treatment programs, which is particularly important when societal resources must be allocated as efficiently as possible. This is not to state that the SCBI is the most superior way of assessing effectiveness of treatment, but it is a concrete way of viewing the returns to society that treatment provides. It is understood that there are many intangible returns which cannot be easily assigned to a dollar value.

\section{REFERENCE NOTE}

1. Sherman, P. S. A comprehensive approach to assessing treatment outcomes. Paper presented at the annual meeting of the National Conference on Community Mental Health Care, Kansas City, Mo., 1978.

\section{REFERENCES}

Alexander, J., \& Messal, J. The planning-programmingbudgeting system in the mental health field. Hospital and Community Psychiatry, 1972, 23, 357-361.

Carten, D., \& Newman, F. L. A client-oriented system of mental health service delivery and program management: $A$ workbook and guide [DHEW Publication No. (ADM) 76-307]. Washington, D.C: U.S. Government Printing Office, 1976.

Conley, R., Conwell, M., \& Arrill, M. An approach to measuring the cost of mental illness. American Journal of Psychiatry, 1967, 124,63-70.

Feldman, S. Problems and prospects: Administration in mental health. Administration in Mental Health, 1972, 1, 4-11.

Fishman, C. A computerized, cost-effectiveness methodology for community mental health centers. In J. B. Sidowski, J. Johnson, \& T. Williams (Eds.), Technology in mental health care delivery systems. Norwood, N.J: Ablex, 1980.

Fox, P., \& Kuldau, J. Expanding the framework for mental health program evaluation. Archives of General Psychiatry, $1968,19,538-544$.

Fox, P., \& RAPPAPORT, M. Some approaches to evaluating community mental health services. Archives of General Psychiatry, 1972, 26, 172-178.

Ginsberg, G., \& Marks, J. Costs and benefits of behavioural psychotherapy: A pilot study of neurotics treated by nursetherapists. Psychological Medicine, 1977, 7, 685-700.

Gunderson, J., \& Mosher, L. The cost of schizophrenia. American Journal of Psychiatry, 1975, 132, 901-906. 
Halpern, J., \& Binner, P. A model for an output value analysis of mental health programs. Administration in Mental Health, $1972,1,40-51$.

Johnson, J., Giannetti, R., \& Williams, T. Computers in mental health care delivery: A review of the evolution toward interventionally relevant on-line processing. Behavior Research Methods \& Instrumentation, 1976, 8, 83-91.

Johnson, J., Williams, T., Giannetti, R., Klingle R, D., \& Ditrme R, H. The auto repair shop model: A vehicle for the transmission of management technology. Professional Psychology, June 1979, pp. 373-380.

Klingler, D., Miller, D., Johnson, J., \& Williams, T. Process evaluation of an on-line computer-assisted unit for intake assessment. Behavior Research Methods \& Instrumentation, 1977, 9, 110-116.

LANyon, R. Mental health technology. American Psychologist, $1971,26,1071-1076$.

LANYON, R. Technological approach to the improvement of decision making in mental health services. Journal of Consulting and Clinical Psychology, 1972, 39, 43-48.

Lyons, J. Operations research in mental health service delivery systems. In J. B. Sidowski, J. Johnson, \& T. Williams (Eds.), Technology in mental health care delivery systems. Norwood, N.J: Ablex, 1980.

Murphy, J., \& Datel, W. A cost-benefit analysis of community versus institutional living. Hospital and Community Psychiatry, $1976,27,165-170$.
Sharfatein, S., \& Nafziger, J. Community care: Costs and benefits for a chronic patient. Hospital and Community Psychiatry, 1976, 27, 170-173.

Shemhan, D., \& AtKinson, J. A comparative costs of state hospital and community-based inpatient care in Texas: Who benefits most? Hospital and Community Psychiatry, 1974, 25, 242-244.

STEIN, L., \& TEST, M. Alternative to mental hospital treatment: I Conceptual model, treatment program, and clinical evaluation Archives of General Psychiatry, 1980, 37, 393-397.

Sutherland, J. Managing social service systems. New York Petrocelli, 1977.

TEsT, M., \& STE IN, L. Alternatives to mental hospital treatment III. Social cost. Archives of General Psychiatry, 1980, 37 409-412.

Weisbrod, R., Test, M., \& Stein, L. Alternatives to menta hospital treatment: II. Economic benefit-cost analysis. Archive. of General Psychiatry, 1980, 37, 400-405.

\section{NOTES}

1. Executive Budget Recommendations of Cook County Fiscal Year 1980; Illinois State Budget, 1981; City of Chicage Budget Recommendations, 1980; the Budget of the United States Government, Fiscal Year 1981: Office of Managemen and Budget, Washington, D.C. GPO: 041-001-00186-7.

2. Illinois Department of Revenue; Department of the Treasury, Internal Revenue Service. 